\title{
URBAN FACILITIES MANAGEMENT: A SYSTEMIC PROCESS FOR ACHIEVING URBAN SUSTAINABILITY
}

\author{
LUKE BOYLE \& KATHY MICHELL \\ UCT-Nedbank Urban Real Estate Research Unit, Department of Construction Economics and Management, \\ University of Cape Town, South Africa.
}

\begin{abstract}
With cities at the forefront of the challenge of achieving global sustainability, a key concern for urban management bodies is to identify ways to promote sustainable development at the urban and sub-urban level. Assessment mechanisms have dominated this field for the past two decades, and sustainable community assessment tools (SCATs) are fast becoming the principal framework adopted by urban planners and developers to drive sustainability. This paper investigates the efficacy and applicability of this approach to urban sustainability. The study aims to establish that the deployment of a management platform, founded in the principles of facilities management (FM), can provide better mechanisms to facilitate the process of achieving urban sustainability. The data were collected by means of survey interviews with key stakeholders who consisted of two main categories: participants from private and public sector engaged in the management and development of sustainable cities. Secondly, developers of the tools were interviewed. The tools evaluated include: LEED for Neighbourhood Development (LEED-ND), BREEAM Communities (BREEAM-C), CASBEE for Urban Development (CASBEEUD), and Green Star Communities (GSC). It was found that the prescriptive and outcomes-based nature of assessment tools do not adequately accommodate institutional and social imperatives of urban sustainability. Additionally, a need for more a robust procedural framework to manage relationships between the various relevant professionals and interest groups was highlighted. This would provide a unified method to facilitate the achievement of urban sustainability. The paper concludes that urban sustainability needs to draw upon the management principles of FM to facilitate more comprehensive development and assessment relevant to the needs of a specific locale. Without a process-oriented method such as this, cities will continue to fall short of their sustainable imperatives.

Keywords: process-oriented sustainability, sustainability assessment, sustainable community assessment tools, sustainable community development, urban facilities management, urban management, urban sustainability.
\end{abstract}

\section{INTRODUCTION}

It has been nearly three decades since the publication of the Brundtland report's 'Our Common Future' [1], outlining the conceptual underpinnings for sustainable development. The document highlighted what is commonly understood as the defining challenge of our generation and called for a re-evaluation of the way humans interact with the environment. Correspondingly, in recent decades global awareness of the threats to environmental sustainability has increased successively [2]. However, the years following the Brundtland report have demonstrated poor progress towards effectively striking a balance between social, economic, and environmental imperatives. This is particularly apparent at an operational level. The current state of Earth confirms the minimal effect the concept of sustainability has brought to global environmental reform. Continued environmental degradation, a steady rise 
in civil unrest, and the ever-widening gap between the rich and the poor have only worsened since the Brundtland report. This is principally a result of human activity. Whilst human activity and its impacts on sustainability is a global concern, the issues associated with addressing sustainability within a global context is such that the scale of the required change is so vast that problems of coordination and cooperation across political units are enormous [3]. In light of this, the urban environment is considered to be the vanguard for addressing global issues regarding sustainability. At this level, meaning is better able to be disseminated from a policy level to the grassroots of implementation.

Nevertheless, urban sustainability, like the broader concept of sustainable development, has many challenges when it comes to implementation. Similarly, many plans for urban sustainability have fallen short of their desired outcomes. Much of these shortcomings are associated with the reductionist approach that many practitioners adopt when devising and measuring urban sustainability. This has resulted in empirically dominant perceptions of sustainability which view issues in isolation and largely ignores aspects that cannot easily be measured. Within the urban context, this ideology is dominant in mechanisms for urban sustainability assessment. The result is a flawed depiction of the complex relationship between human activity and its outcomes. Therefore, assessment has a limited application on many dynamic factors associated with urban sustainability. An emergent product of urban sustainability assessment is the sustainable community assessment tool (SCATs). SCATs provide third-party verification for community scale developments and have seen a surge in popularity by planners and developers in the past decade. Amongst the most popular of such tools are: LEED-ND, BREEAM-C, CASBEE-UD, and GSC. These tools will be evaluated to investigate the applicability of SCATs as an instrument to deliver sustainable cities. SCATs represent a performance-based outlook towards sustainability that prioritises measurable aspects of sustainability. It ignores more meaningful strategies that pay wider recognition to the depth of sustainable development issues.

Innovative new ways to address the inefficacy of responses to urban and global unsustainability need to be introduced. The paper proposes a shift away from technocentric methods of implementing urban sustainability towards a process-oriented methodology that incorporates the principles of systems thinking. An emergent concept within the field of facilities management $(\mathrm{FM})$ is an appropriate response to these challenges. FM is a strategic management model that has ascended to the top of the corporate agenda in recent decades. It is an interdisciplinary field that integrates the processes within an organisation to maintain and develop services which support and improve its primary activities [4]. Michell [5] asserts that the application of these principles at an urban, multiple-building, scale can provide an effective means to promote urban sustainability. This emergent concept is known as Urban Facilities Management (UFM). The application of these management principles at a city-scale provides a collaborative platform that can empower and engage any number of relevant stakeholders involved in the sustainable development of communities and cities.

The investigation also explores the deficiencies in traditional responses to sustainable development, sustainability assessment, and the application of community-scale assessment tools. Adopting procedural methods to institute urban sustainability is an effective means of accelerating urban sustainability.

Findings are based on interviews conducted with key stakeholders involved in sustainable community development in North America. There are a number of reputable SCATs that originate out of North America, and the region is considered to be an innovator within the field of sustainable community development, and corresponding assessment tools. 


\section{INEFFICIENCIES OF CONVENTIONAL ATTEMPTS TO IMPLEMENT SUSTAINABILITY}

Defining the concept of sustainable development has proven to be problematic. The challenge of defining its practical implementation is even greater [6]. There are huge difficulties trying to build global consensus amongst nations with diverse and conflicting values, perceptions, economic systems, ecologies and political systems to mention a few. Distinct development trajectories in various countries underline the notion that no single strategy will apply equally in different countries [6]. Concepts such as 'sustainable world' have in some cases become meaningless to people as they require such levels of abstraction that they are not relevant to daily life [3]. Consequently, sustainability practitioners have sought an international language of measurement and analysis to build consensus through the use of metrics. This requires measuring technical aspects that demonstrate a tenuous link between human activity and sustainability. These empirical outcomes are then used to measure progress and inform policy relating to sustainability.

A further problem with technocratic solutions to sustainability is that the relations of dominance are left in place which dismisses any attempt to address much larger structural problems [3]. For the most part, it is these structures that are responsible for many of the decisions that have caused widespread environmental damage [7]. In this vain, it is reasonable to imagine how, under the stewardship of dominant political and economic structures, sustainability could serve to strengthen economic and social conditions which support unsustainable practices [3]. Accordingly, there is a fundamental need to address the structures of human interaction and activity to reverse their unsustainable consequences.

The dominant ideology behind implementing sustainability is the view that sustainable development is an outcome and not a process. Despite the fact that founding documentation, like 'Our Common Future' established sustainable development as a process. Most practitioners reduced the description of sustainable development to methods that are better suited to scientific endeavour. Consequently, many evade meaningful attempts to engage with the concept as a process by prioritising empirically quantifiable outcomes [6]. This means that assessment and policy is often guided by what can be measured as opposed to what should be measured [8]. Not only does this disregard the complexity and inter-dependencies inherent to sustainable development, it also under-represents social aspects of sustainability which have no clear mechanisms to quantify. As such, various attempts to institute sustainability are disproportionately skewed towards ecological concerns.

\section{URBAN SUSTAINABILITY}

The percentage of Earth's urban population is projected to rise to $66 \%$ by the year 2050 [9]. The pathway of urban development in the decades preceding 2050 will play a crucial role in issues such as climate change and natural resource depletion [10]. Cities are the nucleus of human activity and the vast bulk of environmental degradation and consumption is concentrated within urban areas [2]. This highlights a causal connection between cities and accelerating global ecological decline [11]. Issues quantifying this connection have proven to be challenging. However, it is important to understand that urban areas are globally integrated and are complex systems that can support and hinder each other in various ways.

Despite this, urban development is the beginning to be seen as a solution to these concerns, and not just a source of them [2]. Cities and their inhabitants can play a pivotal role in achieving global sustainability [11]. Urban sustainability is fundamentally reliant on the ability of urban stakeholders to work together in ensuring innovative, equitable and economically via- 
ble action is taken. Fostering these collaborative actions is best achieved at the local or community scale.

3.1 Sustainable development at the local level: toward sustainable community development

Unsustainable human practices are ultimately a consequence of the way human activity is organised and carried out. To this end, it is logical to seek reparations at the source of human activity. This is most appropriately examined at the level in which human life is experienced; the sub-urban or community level. It follows that the community is the basic unit of urban development [12], and the minimum scale to account for social, economic, and institutional aspects of sustainability [13,14]. The community scale is where the consequences of environmental degradation are most acutely experienced, and where successful intervention is most visible [3]. It stands to reason that sustainability must be achieved at a local level to be realised on a global scale [15].

Local Agenda 21 (LA21) provided the first formal recognition of the importance of articulating strategies for sustainability at the local level. Its publication drove a number of community-level responses to global sustainability. Despite this, little evidence has suggested a widespread dissemination of this framework into effective strategies. This is because it provides little insight into the vehicles that manage the complex process of sustainable community development. As a result, implementing sustainable communities focus on the outcomes of planning, design and construction [12]. Despite LA21's shortcomings, it did highlight that community-based responses to sustainability are crucial for the fulfilment of global sustainability. The lack of locally relevant and sensitive information is another cause of LA21's failures. People living at the local level are able to identify and respond to local opportunities and challenges. Engaging with this allows for the design of policies and structures that are sensitive to the contextual conditions inherent to a particular place [3]. What is missing are better mechanisms to satisfy the fulfilment of community development processes. Aims of the process at this level are: establishing a common vision, assessing existing local conditions, developing shared strategies, and establishing a framework for the sustained implementation of these strategies [16]. It follows that there is a need for an improvement in the way information feeds back into decision making at the local level $[6,16]$. Thus, a community's ability to articulate what needs to be sustained is an important part of the development process.

Sustainable community development can exhibit that sustainability can be achieved on a broader scale as it places the concept of sustainability within a context where it can be validated as a process. Therefore, as successes become tangible aspects of daily life, the concept's legitimacy and acceptance, which has thus far proved elusive, can be secured [7]. Devising operative strategies for sustainability entails striking the challenging balance between creating explicit meaning, while not being overly prescriptive. Since meaning is derived through context, a framework that incorporates a community's context will more effectively promote sustainability. Linking context and implementation is best derived through the use of systems thinking.

\subsection{Systemic view of urban sustainability}

Earlier in the paper, it was reasoned that attempts to address sustainability have been ineffective as they rely on empirically dominated measures to analyse and solve the issues related to 
sustainability. This represents a dominant scientific practice known as reductionism. This laboratory-like approach to complex phenomenon reduces them into elementary parts and processes [17]. The logic of isolating situations into smaller parts of manageable information has been translated into strategies for sustainable development. The problem with reductionism is its failure to generate a reliable understanding of reality as the basis for imagining transitions to a more sustainable future [18]. Despite the profound advances in science and technology reductionism has gifted physical science, it has had much less success in the biological and social sciences [19]. Given that biological and social sciences form an integral part of the issues surrounding sustainability, it is reasoned that reductionist approaches are inappropriate for devising effective strategies for sustainability. It stands to reason that a different kind of thinking is required; that views the actors within complex situations holistically. To achieve this; linear, reductionist, and mechanistic thinking needs to be replaced with; nonlinear, organic thinking: systems thinking [20]. Systems thinking represents a fundamental shift in scientific rationale where the inter-dependencies and interactions of the components within a system are assigned the same importance as the components themselves. A holistic acceptance of systemic connections will better serve the needs of sustainability [20, 21]. Boulding [19] introduces the viewpoint of Earth as a general evolutionary system with a complex structure of many different systems. With this in mind, and the reality that sustainable development is a global concern, it is a natural progression to view sustainable development in terms of these integrated systems. Therefore, what is needed is a better understanding of the complex systems that are central to the concept of sustainable development; social systems and eco-systems.

A further development within the field of systems thinking is the concept of complexity. Complexity theory is an emerging science that represents multi-disciplinary efforts to understand the nature of the world, and how it has evolved in both natural and human systems [22]. The importance of social/human elements in the attainment of sustainability has been demonstrated throughout this paper. Following this logic, a means of achieving better results toward sustainability entails a deeper inquiry into social systems and their interactions with the environment. These systems are known as complex systems. To this end, sustainable development is an issue of complex systems [20]. A complex system is a collection of entities interconnected by an intricate web of relations which depend greatly on the transmission of information [23]. Complexity is a result of the interaction between these entities that classical analytical approaches have failed to explain [24]. Unlike mechanistic components; components of a complex system are more intricate in their structure, more unstable, and more affected by the workings of the system of which they are a part [23]. These descriptions more effectively account for dynamic human activity, and its interactions with nature than reductionist notions. Hence, complexity principles are central to understanding our world and the current global challenges of social and environmental sustainability [25]. The implication of complexity on sustainability is the acceptance of uncertainty and non-linearity. This stresses the need to move away from measurable outcomes towards an introspective examination of the mechanisms that inform human activity and its relationship with the environment.

\section{SUSTAINABILITY ASSESSMENT}

The introduction of Agenda 21 in 1992 placed a major emphasis on sustainability assessment. However, the growth of assessment of this field has proliferated a disregard towards systemic outlooks of sustainability. The resultant indices do not depict the reality of the world by any measure of accuracy. Moreover, the unpredictable and complex flux of human activity 
questions the reliability and validity of many conventional approaches to sustainability assessment. Nonetheless, being able to measure the success and failures of sustainable strategies is vital. The introduction of assessment has helped to facilitate the communication of progress across various actors which are keys to mutual success in moving toward sustainability [26]. To this end, sustainability assessment of urban design and development is increasingly being seen as an indispensable tool for informed decision making for sustainability [27]. Whilst the importance of sustainability assessment cannot be disputed, the manner in which it is conducted can. Through the logic of reduction it is reasoned that the level of progress of sustainable interventions can be assessed by measuring the causes of issues related to sustainability such as greenhouse gas emissions or air quality. This is achieved by assigning indicators to quantify the sources of the issues without considering their broader connections. This conventional approach to assessment lacks any concrete causality to link an intervention and its effect on sustainability. Additionally the mechanistic ideologies that support assessment typically limit measurement to a single dimension of economic, social or environmental unsustainability [28]. This offers little consideration of the inter-dependencies of complex social systems. In order for complex social systems to adapt and provide enough resilience to be sustainable, they require effective feedback mechanisms [29]. The empirical nature of sustainability assessment means that they are inept at providing reliable feedback about long-term changes since the exogenous and endogenous factors influencing sustainability are always changing [30].

Prevailing assessment techniques largely ignore community-scale measurement in favour of national-level metrics. Correspondingly, assessment rarely provides information that is relevant to manage individual actions [28]. As a result, the human factor of sustainability is vastly under-represented by sustainability assessment. A more systemic approach to assessment is essential for more accurate monitoring of the complex social and environmental systems at play at the local level $[8,29]$. Furthermore, vehicles of assessment require greater sensitivity and specificity to the values held in a particular area. Here, individuals at a community level could manage their behaviour with reference to a broader movement (global sustainability) in terms that are related and understandable to that community [28]. There is a growing consensus amongst academics that assessment indicators need to be more representative of local conditions and more aligned with the values of that audience [28, 29]. This serves to empower a local population to attain a deeper understanding of the concept of sustainability to best respond to the sustainability threats and opportunities of a particular place.

The value and importance of sustainability assessment cannot be denied. However, it is clear that the manner in which assessment is conducted is as vital to delivering meaningful information about a particular issue than the assessment itself.

\subsection{Sustainable community assessment tools}

The previous section put forward the notion that sustainability assessment will have little effect on global sustainability if it is not properly articulated at a local level. In response to this, myriad of different methods have emerged to assess sustainability within the urban environment, all with varying resolution, scope, and application. In the last decade a number of popular assessment tools have emerged that assess the sustainability of urban development [27]. These are more commonly known as SCATs. These tools expanded out of the success of the green building movement and are a useful guide for local governments and developers 
to incorporate sustainability into their development practices. Creating appropriate assessment tools for communities can more effectively evaluate and facilitate decision making for sustainable urban development [12]. The tools selected for this investigation are LEED-ND, BREEAM-C, CASBEE-UD, and GSC. The former three tools were selected based on their global dissemination and application. Furthermore, they are seen as the basis for most assessment rating tools around the world [27]. Green Star was chosen because it too has international recognition but more importantly it demonstrates a deeper focus on urban governance within its framework.

LEED-ND was developed by the United States Green Building Council in 2009 and has five main focus areas, namely: smart growth and linkages; neighbourhood pattern and design; green infrastructure and buildings; innovation and design process; regional priority credit. LEED-ND has been used to assess neighbourhood sustainability in many projects outside the United States [27]. This is the most popular global rating tool. BREEAM-C was developed in the United Kingdom (UK) by BRE Global in 2009. The tool, in its current iteration, is split-up into five key themes: governance; social and economic well-being; resources and energy; land-use and ecology; transport and movement. This tool deals with both existing and new neighbourhoods and has also been used in countries outside the UK. CASBEE-UD is a Japanese rating tool designed for urban development. It was developed in 2007 and was the first community-scale assessment tool. The tool categorises six main themes: natural environment; service functions for the designated area; contribution to the local community; environmental impact on microclimates, façade, and landscape; social infrastructure; management of the local environment. CASBEE-UD is the third most popular SCAT. GSC was launched by the Australian Green Building Council in 2012. The tool is considered to be a synthesis of LEED-ND and BREEAM-C. Unlike the other two tools GSC did not evolve out of a green building rating tool. The six main features of this tool represent: governance; design; liveability; economic prosperity; environment; innovation. GSC is one of the few tools that has attempted to address differing local contexts.

\subsubsection{Issues with sustainable community assessment tools}

The benefits of applying assessment to the community level are well understood. However, the challenges involved with managing the increasing complexities of human interaction as the scope of assessment expands is a significant challenge for SCATs. There is a general consensus that these rating systems are dominated by environmentally based issues [13, 27, $31,32]$. As a result the tools have been criticised for under-performing in social, economic, and institutional aspects of sustainability [32]. Institutional sustainability refers to the interactions between government, and non-government actors in decision making, as well as the set of norms, laws and regulations governing these interactions [31]. Respondents highlighted that SCATs do not provide an adequate framework for collaboration between the stakeholders engaged in a development project.

The lack of consideration for institutional and socio-economic aspects of sustainability is mainly attributed to the building-centric approach of assessment tools, a hangover from their green building predecessors. Tools such as LEED-ND, BREEAM, and CASBEE-UD exhibit an approach that almost exclusively considers the physical and material properties of built environment [32]. To this end, it is conceivable that SCATs serve to uphold reductionist ideologies.

Another major concern with the application of SCATs is their lack of ability to account for differing contexts. Whilst it is understood that the tools were designed for their specific countries 
they lack the sensitivity to adapt to the specific conditions of a local community. It is stressed that tools should be customised to be sensitive to context and development type [31].

The tools have had a massive impact in stimulating market recognition for urban areas with low environmental impact through assessment and certification [27]. Most respondents noted this achievement. However, the result has meant that obtaining certification can become a solely marketing-driven decision where developers embark to chase points [32]. Existing studies, and data from this study, revealed that developers of LEED-ND projects favour criteria with higher point weighting [31]. Thus, it is possible that tools are used to ensure the marketability of a community rather than its sustainability.

The vast majority of assessment tools are expert-driven and do not adequately involve a comprehensive assortment of stakeholders [31,32]. Consequently, the opinion and knowledge of local actors is seldom included in the assessment process. All of the respondents agreed that community engagement is central to effective sustainable community development. Therefore, there is a need for a greater inclusion of citizen's opinion in the application of SCATs [32]. Assessment needs to be dynamic rather than static, and cater solely to the needs of the community of application. Thus, the resultant assessment serves to complement a larger sustainable development process, and is not the process itself.

\section{TOWARDS A PROCESS-BASED APPROACH TO URBAN SUSTAINABILITY}

'Our Common Future' outlined many pragmatic ideologies that support sustainable development. Some of these have been adopted into the consciousness of sustainability practitioners, whilst others have not, namely: viewing sustainability as a process, and institutional changes to government and economic institutions. Sustainability is a process which requires tradeoffs among contending groups with different interests, priorities, and perceptions. Poor mechanisms to manage these trade-offs have created significant roadblocks for implementation. This suggests a need to delve deeper into decision-making by exploring the strategies, motivations, and capacities of role-players at the urban level [26]. Such an intervention requires a greater acknowledgement of the complexities and systemic interactions that exist in cities. Bagheri \& Hjorth [33] stress a shift away from mechanistic thinking to develop strategies that can manage complex issues with high levels of uncertainty. Dominant reductionist views overlook fundamental aspects of the urban space, namely the high concentration of social actors. Sachs-Jeantet [34] calls for a reconceptualisation of the empirical and intellectual tools for the study of urban processes as they are based on a 'radically different urban morphology' and are not applicable to emergent issues in urban areas.

What is proposed is a means of addressing the complexities and uncertainties that exist in urban environments. This facilitates decision making that better reflects the indeterminate realities of the human experience in the built form. Here, goals and outcomes emerge out of a process of inclusive negotiation rather than predefined standards [35]. A central feature of a process-orientated approach to sustainability is an iterative process of inquiry into complex situations. These offer a multitude of differing perspectives to negotiate and implement feasible actions to improve said situation. The process of learning with the participation of stakeholders is considered to be an essential strategy for sustainable development [33].

\section{A SYNTHESIS OF UFM AND PROCESS-ORIENTED SUSTAINABILITY}

UFM is a considered to be a 'new alignment' of FM. This emergent concept presents the idea of adapting FM principles from a 'micro', building level, to the 'macro' level, where the city itself is seen as the facility. This can create an effective standard in which to manage an urban 
precinct [5]. This new branch of research opens up the already broad sphere of FM to disciplines that include: urban development; urban planning and policy; governance; and public participation, to promote sustainable urbanisation [36]. FM's role in the urban context is thus conceptualised as a flexible platform that enables new, innovative integration of private and public sector services in order to benefit society at the precinct scale [5]. It is also noted that FM is key towards opening up broader social issues, and is likely to drive the creation of an inclusive and creative urbanity that prioritises sustainability. The creation of a sustainable urban environment requires the collaborative efforts of many stakeholders with different roles and values, sharing meaningful information and learning; through innovative response to feedback [29]. The necessity for urban governance is well understood by sustainability practitioners, yet evidence of these platforms are often absent in the urban space. UFM can fill the gap left by the decline of urban governance through the creation of a holistic platform that integrates and empowers stakeholders to take reflective action. Ultimately, it is believed that UFM holds the potential to facilitate systemic solutions to issues of implementation that have plagued sustainable development for the past three decades.

Embracing the underlying concepts around 'space, place and people' that underpin FM [5], it is posited that UFM can form the basis for a process-oriented approach to urban sustainability that can complement assessment methods whilst providing concrete mechanisms to achieve the assessment goals.

\section{CONCLUSION}

Cities are at the forefront of the existential challenge of sustainability. Moreover, the community level is where efforts of implementation for global sustainability should be focused. Strong motivation for the mobilisation of communities to promote sustainability was established in this study. However, mechanisms for harnessing this is poorly demonstrated by urban sustainability frameworks. Additionally, the systemic concept of sustainability is yet to disseminate into the broader consciousness of society. This is exhibited by SCATs that extend precedence to environmental factors of sustainability with little regard to their broader relations to social, economic, and institutional factors.

The paper addresses the need for better mechanisms to implement and assess urban sustainability. SCATs rely heavily on expert actors and performance outcomes which inaccurately quantify sustainability. The study found that frameworks that drive urban sustainability must be less prescriptive and pay greater attention to the collaborative processes inherent to sustainable development within a given setting. A process-oriented approach to urban sustainability can better foster a collaborative response where decision making is inclusive and consistent with the systemic nature of the world. Therefore, this intervention is more likely to accelerate locally responsive outcomes towards urban sustainability than prescriptive SCATs. Such a process can be founded in the principles of UFM. This approach provides a flexible and holistic platform to manage social, economic, ecological, and institutional dimensions of sustainability. Without such a consideration urban sustainability initiatives will continue to fall short of their objectives.

\section{REFERENCES}

[1] World Commission on Environment and Development (WCED), Our Common Future, Oxford University Press: Oxford and New York, 1987.

[2] Metzger, J. \& Olsson, A. (eds), Sustainable Stockholm: Exploring Urban Sustainability in Europe's Greenest City, Routledge: New York, 2013. 
[3] Bridger, J. \& Luloff, A., Toward an interactional approach to sustainable community development. Journal of Rural Studies, 15, pp. 377-387, 1999.

http://dx.doi.org/10.1016/S0743-0167(98)00076-X

[4] British Institute of Facilities Management Web site, available at http://www.bifm.org. uk/bifm/home

[5] Michell, K., Urban facilities management: a means to the attainment of sustainable cities? Journal of Facilities Management, 11(3), 2013.

http://dx.doi.org/10.1108/jfm.2013.30811caa.001

[6] Alberti, M. \& Susskind, L., Managing urban sustainability: introduction to the special issue. Environmental Impact Assessment, 16, pp. 213-221, 1996. http://dx.doi.org/10.1016/S0195-9255(96)00070-4

[7] Yanarealla, E. \& Levine, R., Does sustainable development lead to sustainability? Futures, 24, pp. 759-774, 1992. http://dx.doi.org/10.1016/0016-3287(92)90105-O

[8] McCool, S. \& Stankey, G., Indicators of sustainability: challenges and opportunities at the interface of science and policy. Environmental Management, 33(3), pp. 294-305, 2004. http://dx.doi.org/10.1007/s00267-003-0084-4

[9] UN, World Urbanization Prospects: The 2014 Revision- Highlights, United Nations: New York, 2014.

[10] Alusi, A., Eccles, R., Edmondson, A. \& Zuzul, T., Sustainable cities: Oxymoron or the shape of the future? Harvard Business School, Working Paper. 2011.

[11] Rees, W. \& Wackernagel, M., Urban ecological footprints: why cities cannot be sustainable- and why they are key to sustainability. Environmental Impact Assessment, 16, pp. 223-248, 1996. http://dx.doi.org/10.1016/S0195-9255(96)00022-4

[12] Xia, B., Chen, Q., Skitmore, M., Zuo, J. \& Li, M., Comparison of sustainable community rating tools in Australia. Journal of Cleaner Production, 109, pp. 1-8, 2015. http://dx.doi.org/10.1016/j.jclepro.2015.08.016

[13] Berardi, U., Sustainability assessment of urban communities through rating systems. Environmental Development and Sustainability, 15(6), pp. 1573-1591, 2013. http://dx.doi.org/10.1007/s10668-013-9462-0

[14] Sharifi, A. \& Murayama, A., Neighborhood sustainability assessment in action: crossevaluation of assessment systems and their cases from the US, the UK, and Japan. Building and Environment, 72, pp. 243-258, 2014. http://dx.doi.org/10.1016/j.buildenv.2013.11.006

[15] Mehta, P., Local Agenda 21: practical experiences and emerging issues from the South. Environmental Impact Assessment, 16, pp. 309-320, 1996. http://dx.doi.org/10.1016/S0195-9255(96)00029-7

[16] Brugmann, J., Planning for sustainability at the local government level. Environmental Impact Assessment, 16, pp. 363-379, 1996. http://dx.doi.org/10.1016/S0195-9255(97)81658-7

[17] von Bertalanffy, L., The history and status of general systems theory. The Academy of Management Journal, 15(4), pp. 407-426, 1972. http://dx.doi.org/10.2307/255139

[18] Swilling, M. \& Annecke, E., Just Transitions: Explorations of Sustainability in an Unfair World, UCT Press: Cape Town, 2012.

[19] Boulding, K., The World as a Total System. Beverly Hills, Sage: California, 1985. 
[20] Hjorth, P. \& Bagheri, A., Navigating towards sustainable development: a system dynamics approach. Futures, 38, pp. 74-92, 2006.

http://dx.doi.org/10.1016/j.futures.2005.04.005

[21] Gladwin, T., Kennelly, J. \& Krause, T., Shifting paradigms for sustainable development: implications for management theory and research. Academy of Management Review, 20(4), pp. 874-907, 1995.

[22] Kiel, D., Knowledge Management, Organizational Intelligence and Learning, and Complexity, Vol. 1, EOLSS: Texas, 2009.

[23] Buckley, W., Sociology and Modern Systems Theory, New Jersey: Prentice-Hall, 1967.

[24] Cilliers, P., Complexity and Postmodernism: Understanding Complex Systems, Routledge: London, 1998.

[25] Wells, J., Complexity and Sustainability, New York: Routledge, 2013.

[26] Shriberg, M., Institutional assessment tools for sustainability in higher education: strengths, weaknesses, and implications for practice and theory. International Journal of Sustainability in Higher Education, 3(3), pp. 254-270, 2002. http://dx.doi.org/10.1108/14676370210434714

[27] Ameen, R.F., Mourshed, M. \& Li, H., A critical review of environmental assessment tools for urban design. Environmental Impact Assessment Review, 55, pp. 110-125, 2015. http://dx.doi.org/10.1016/j.eiar.2015.07.006

[28] Dahl, A., Achievements and gaps in indicators for sustainability. Ecological Indicators, 17, pp. 14-19, 2012. http://dx.doi.org/10.1016/j.ecolind.2011.04.032

[29] Innes, J. \& Booher, D., Indicators for sustainable communities: a strategy building on complexity theory and distributed intelligence. Planning Theory \& Practice, 1(2), pp. 173-186, 2010.

http://dx.doi.org/10.1080/14649350020008378

[30] Moffatt, I. \& Hanley, N., Modelling sustainable development: systems dynamic and input-output approaches. Environmental Modelling \& Software, 16, pp. 545-557, 2001. http://dx.doi.org/10.1016/S1364-8152(01)00024-X

[31] Sharifi, A. \& Murayama, A., A critical review of seven selected neighbourhood sustainability assessment tools. Environmental Impact Assessment Review, 38, pp. 73-87, 2013. http://dx.doi.org/10.1016/j.eiar.2012.06.006

[32] Komeily, A. \& Srinivasam, R., A need for balanced approach to neighbourhood sustainability assessment: a critical review and analysis. Sustainable Cities and Society, 18, pp. 32-43, 2015.

http://dx.doi.org/10.1016/j.scs.2015.05.004

[33] Bagheri, A. \& Hjorth, P., Planning for sustainable development: a paradigm shift towards a process-based approach. Sustainable Development, 15, pp. 83-96, 2007. http://dx.doi.org/10.1002/sd.310

[34] Sachs-Jeantet, C., Managing social transformation in cities: a challenge to social sciences, 1996.

[35] Robinson, J. \& Cole, R., Theoretical underpinnings of regenerative sustainability. Building Research \& Information, 43(2), pp. 133-143, 2015. http://dx.doi.org/10.1080/09613218.2014.979082

[36] Drion, B., Melissen, F. \& Wood, R., Facilities management: lost, or regained? Facilities, 30(5/6), pp. 254-261, 2012.

http://dx.doi.org/10.1108/02632771211208512 